\title{
Microstructural Evolution and Properties of a Hot Extruded and HPT-processed Resorbable Magnesium WE43 Alloy
}

Dexue Liu ${ }^{\mathrm{a}, \mathrm{b}}$, Xin Pang ${ }^{\mathrm{a}}$, Denglu Li ${ }^{\mathrm{a}}$, Chenggong Guo ${ }^{\mathrm{a}}$, Jittraporn Wongsa-Ngam ${ }^{\mathrm{c}}$, Terence G. Langdon ${ }^{\mathrm{d}}$ Marc A. Meyers ${ }^{\mathrm{b}}$

${ }^{a}$ State Key Laboratory of Advanced Processing and Recycling of Non-ferrous Metals, Lanzhou University of Technology, Lanzhou 730050, China

${ }^{b}$ Department of Aerospace and Mechanical Engineering, University of California, San Diego, CA 92093-0411, USA

${ }^{c}$ Department of Mechanical Engineering, Faculty of Engineering,

King Mongkut's Institute of Technology Ladkrabang, Bangkok 10520, Thailand

${ }^{d}$ Departments of Aerospace \& Mechanical Engineering and Materials Science,

University of Southern California, Los Angeles, CA 90089-1453, USA

\section{Corresponding Author:}

Dexue Liu

PH.D, Associate Professor of Materials Science and Engineering, Visiting Scholar in UCSD Institution: State Key Laboratory of Advanced Processing and Recycling of Non-ferrous Metals School of Material Science and Engineering, Lanzhou University of Technology Address: Langongping road 287, Lanzhou City, Gansu Province 730050, P.R. China Phone: (86)-13919947009(cell)

Fax: $\quad$ (86)-931-2976702

Email: dexeliu@hotmail.com

\section{Acknowledgments}

Dexue Liu was supported by the National Nature Science Foundation of China under Grant No.51365029 \& No.51664041. This work was also supported in part by the Fundamental Research Funds for the Universities in Gansu Province and Longyuan Youth Innovation and Entropreneurship Projects. Marc Meyers acknowledges support by National Science Foundation Grant 1006931 and University of California Research Laboratories Grant 09-LR-06-118456-MEYM. Jittraporn WongsaNgam and Terence G. Langdon were supported by the National Science Foundation of the United States under Grant No. DMR-1160966. 


\begin{abstract}
Disks of an extruded magnesium WE43 alloy are processed by high-pressure torsion (HPT) under a pressure of $6.0 \mathrm{GPa}$ for 5 and 10 turns at room temperature and the evolutions of microstructure and mechanical properties are investigated in detail. Excellent grain refinement is achieved by HPT processing with a reduction in grain size from an initial value of $\sim 12 \mu \mathrm{m}$ to a final value of 200-300 nm after 10 turns. The microhardness increases significantly with HPT processing but low hardness values are recorded at the centers of the disks even after 10 turns. The results of tensile testing at room temperature demonstrate that the tensile strength initially increases and then decreases while the elongation decreases. The decrease in strength is attributed to the inhibitory effect of grain boundary on dislocation movement decreased. Observations of the fracture surfaces reveal a corresponding transition of the fracture mode from ductile to brittle.
\end{abstract}

Keywords: Resorbable magnesium alloy, Hot extrusion, High-pressure torsion, Microstructure evolution, Grain refinement 


\section{Introduction}

Magnesium alloys have received considerable attention over the last two decades because of their potential as biomaterials due to their excellent biocompatibility and mechanical compatibility compared with other biomaterials such as polymers and ceramics, especially regarding in vivo cardiovascular disease treatment. ${ }^{[1,2]}$ In practice, polymers and ceramics generally fail to provide sufficient strength, ductility or compatibility in clinical applications. ${ }^{[3,4]}$ There have been numerous attempts to achieve superior biomedical metals using approaches such as alloy design and preparation and through modifications to the mechanical properties, ${ }^{[5-9]}$ corrosion resistance and through surface modification. ${ }^{[10,11]}$ However, it is difficult with magnesium alloys to achieve precise plastic deformation because of their poor ductility due to their hexagonal crystal structure and limited number of active slip systems. As a consequence, the application of magnesium alloys tends to be limited and it is necessary, therefore, to introduce new metal forming technology to improve the mechanical properties of these materials.

It is now well established that fine grain strengthening may be used to improve the mechanical properties of these alloys by introducing changes in their microstructure. ${ }^{[12]}$ For biodegradable magnesium alloy stents, it is important to improve the strength, hardness and toughness and also to simultaneously improve the forming capability.

Significant grain size refinement may be achieved by subjecting materials to severe plastic deformation (SPD). ${ }^{[13-17]}$ This approach can produce an ultra-fine crystal structure and even a nanocrystalline structure under optimum conditions, thereby leading to improved mechanical properties in terms of the Hall-Petch relationship. ${ }^{[18]}$ Equal-channel angular pressing (ECAP) and high-pressure torsion (HPT) are two of the most attractive SPD processing techniques where ECAP denotes the pressing of a bar through a die constrained within a channel that is bent through an abrupt 
angle and HPT denotes placing a disk in depressions between two massive anvils and then subjecting to a pressure, $P$, and concurrent torsional straining. ${ }^{[19,20]}$ Generally, HPT is now conducted under quasi-constrained conditions where the disks have diameters of $\sim 10-20 \mathrm{~mm}$ and thicknesses of $\sim 0.8$ $\mathrm{mm}$ and there is some limited outflow of material around the periphery of the disk during the processing operation. ${ }^{[21]}$ Several results have now established that, by comparison with other SPD techniques including ECAP, processing by HPT produces materials having both smaller grain sizes and a higher fraction of grain boundaries having high angles of misorientation. ${ }^{[22,23]}$ Nevertheless, many of the reports for HPT processing are based on fcc and bcc materials and the microstructures and properties of hexagonal close-packed materials have received less attention because of the weaker plasticity of these materials.

The present investigation was initiated to study the properties of a WE43 (Mg-4.2Y-2.4Nd0.6Ce( $\mathrm{La})-0.5 \mathrm{Zr}$ ) alloy prepared by vacuum melting and then subjected to hot extrusion and SPD processing by HPT. Very significant grain refinement was achieved using this processing sequence and the material was then examined to evaluate the microstructural evolution and the mechanical properties of the HPT-processed alloy by comparison with the as-extruded material.

\section{Experimental material and procedures}

\subsection{Preparation of materials}

The composition of the alloy was $\mathrm{Mg}-4.2 \mathrm{wt} \% \mathrm{Y}-2.4 \mathrm{wt} \% \mathrm{Nd}-0.6 \mathrm{wt} \% \mathrm{La}(\mathrm{Ce})-0.5 \% \mathrm{Zr}$ alloy. Commercial purity $\mathrm{Mg}(99.99 \mathrm{wt} \%), \mathrm{Mg}-20 \mathrm{wt} \% \mathrm{Y}, \mathrm{Mg}-20 \mathrm{wt} \% \mathrm{Zr}, \mathrm{Mg}-20 \mathrm{wt} \% \mathrm{Nd}$ and $\mathrm{Mg}-20 \mathrm{wt} \%$ $\mathrm{Ce}(\mathrm{La})$ intermediate alloys were melted in a vacuum induction furnace (Lanzhou University of Technology, China) at a temperature of $800^{\circ} \mathrm{C}$ in a protective high purity argon atmosphere. A homogeneous annealing treatment was performed at $400^{\circ} \mathrm{C}$ for $4 \mathrm{~h}$. Then the cast ingot was machined into a cylindrical plate with a diameter of $72 \mathrm{~mm}$ and height of $20 \mathrm{~mm}$ after the oxide skin was 
removed.

\subsection{Hot extrusion}

The extruded rods were obtained at an extrusion speed of $4 \mathrm{~mm} \mathrm{~s}^{-1}$ using a $3150 \mathrm{kN}$ hydraulic pressure squeezing facility (Tianduan Press Co. Ltd. China).The extrusion die was heated to a temperature of $400 \pm 5^{\circ} \mathrm{C}$ together with the sample to ensure they were in an isothermal state prior to extrusion. The as-extruded rod diameter was $12 \mathrm{~mm}$ representing an extrusion ratio of $36: 1$ where the initial diameter was $72 \mathrm{~mm}$. Subsequently, the extruded material was machined into rods with diameters of $10 \mathrm{~mm}$.

\subsection{HPT deformation}

The initial rods with diameters of $10 \mathrm{~mm}$ were annealed at $400^{\circ} \mathrm{C}$ for $4 \mathrm{~h}$ and then cut into disks with diameters of $10 \mathrm{~mm}$ and thicknesses of $0.8 \mathrm{~mm}$. These disks were processed by high-pressure torsion at room temperature using a quasi-constrained HPT facility. This procedure was performed for numbers of revolutions, $N$, of 5 and 10 turns under an imposed constant hydraulic pressure of 6.0 $\mathrm{GPa}$ and a constant rotational speed of $1 \mathrm{rpm}$.

\subsection{Microstructural characterization}

The microstructures of all samples and the elemental distributions were examined using a scanning electron microscope (SEM) equipped with an energy dispersive spectrometer (SEM-EDS, QUANTA-450FEI, USA) after polishing and etching with a mixture of $4 \mathrm{ml}$ nitric acid and $96 \mathrm{ml}$ ethanol ( $\geq 99.7 \%)$. The internal microstructures were examined by transmission electron microscopy (TEM, JEM-2010,Japan)and by recording selected area electron diffraction (SAED) patterns. First, the TEM samples were mechanically polished to $\sim 40 \mu \mathrm{m}$. Second, $3 \mathrm{~mm}$ foils were cut from the midradius positions of the HPT disks. Finally, thinning was undertaken using $5 \mathrm{kV} \mathrm{Ar}{ }^{+}$ions and an angle 
of $4^{\circ}$ from both sides until perforation. The constituent phases of the extruded samples and the HPT disks were examined by X-ray diffraction (XRD, D/max-2400, Japan) using $\mathrm{Cu} \mathrm{K}_{\alpha}$ radiation.

\subsection{Mechanical testing}

After HPT processing, the disks were mounted and polished to mirror-like conditions. Each value of the Vicker microhardness was then recorded using a microhardness tester (HX-1000, Shanghai Changfang Optical Instrument Co. Ltd, China) equipped with a Vickers indenter under an applied load of $50 \mathrm{~g}$ and a dwell time of $12 \mathrm{~s}$. Two different procedures were used to obtain detailed microhardness values for each disk. First, the microhardness values were recorded along the diameters of the disks using incremental distances of $0.3 \mathrm{~mm}$. For these values, $\mathrm{Hv}$ was obtained from the average value of four different hardness measurements uniformly located around the selected position at distances of $\sim 0.15 \mathrm{~mm}$ from the selected point. Second, the values of microhardness were recorded following a rectilinear grid pattern with incremental distances of $0.3 \mathrm{~mm}$ between points and following two sets of parallel lines. Subsequently, all of these microhardness values were used to plot the hardness distributions in three-dimensional space.

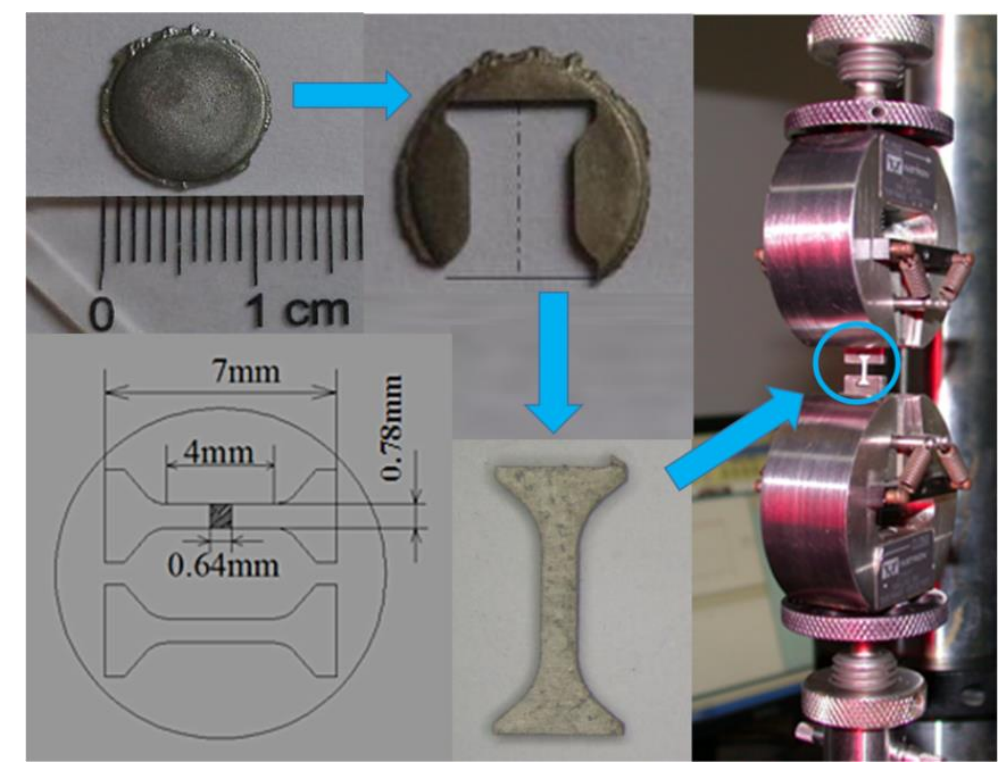

Figure 1 The position of the tensile samples in the processed disk and size. 
Tensile tests were also performed on a microcomputer-controlled testing machine (Intron5848, USA) equipped with a video extensometer with a strain rate of $0.3 \mathrm{~min}^{-1}$ at room temperature. The tensile gauge lengths and the cross-sectional areas of the samples were $4 \mathrm{~mm}$ and $(0.78 \times 0.64) \mathrm{mm}^{2}$ as shown in Figure 1, respectively. The yield strength, tensile strength and elongation were recorded directly from the stress-displacement curves.

\section{Results and discussion}

\subsection{Microstructure}

The microstructure and composition distribution of the WE43 alloy in the as-extruded sample and in disks processed by high-pressure torsion are illustrated in Figure 2. Figure 2(a) shows that the microstructure of the as-extruded sample prior to HPT consists of equiaxed grains with an average gain size of $\sim 12 \mu \mathrm{m}$ and with some secondary phases along the grain boundaries. These secondary phases are distributed in a spotty and intermittent fashion.
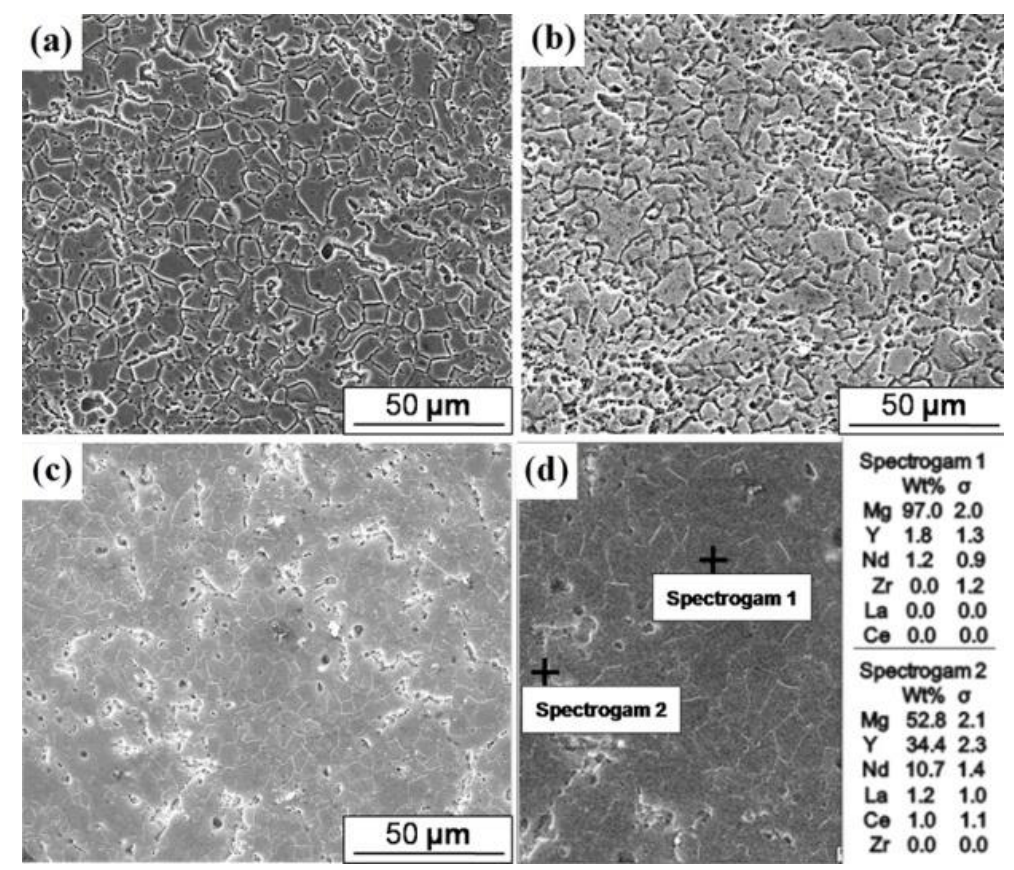

Figure 2 SEM photographs of the WE43 alloy: (a) showing the initial as-extruded sample; (b) and (c) showing the structure after HPT processing for 5 turns and 10 turns respctively; (d) showing EDS after HPT processing for 10 turns. 
As shown in Figures 3 and 2(d), the $\alpha-\mathrm{Mg}$ matrix phase and the secondary phases consist of $\mathrm{Mg}_{24} \mathrm{Y}_{5}, \mathrm{Mg}_{41} \mathrm{Nd}_{5}$ and $\mathrm{Mg}_{12} \mathrm{Nd}$ as determined by the XRD as well as EDS. Figures 2(b) and 2(c) show the microstructural evolution of the alloy processed by HPT near the centers of the disks. In contrast to the as-extruded sample, no remarkable change appears in the near center of the disk after HPT deformation for 5 turns in Figure 2(b), the microstructure of the $\alpha$-Mg matrix is not obviously refined, the average grain size is $\sim 10 \mu \mathrm{m}$ and the grain boundaries are easily visible. With an increase in the numbers of rotations, there is grain refinement and the grain size slightly decrease after HPT through 10 turn in Figure 2(c). For this condition, there is the same secondary phase along the grain boundaries. This means that the amount of the secondary phase increases and the grain boundaries generally become less distinct with increasing deformation. A similar report of the formation of diffuse boundaries was described in very early experiments on metals processed by SPD techniques and it was attributed to the formation of non-equilibrium grain boundaries containing an excess of extrinsic dislocations. ${ }^{[24]}$ No new peaks were generated in the XRD patterns after HPT processing compared with the as-extruded sample and also there was no evidence for the formation of any new phases.

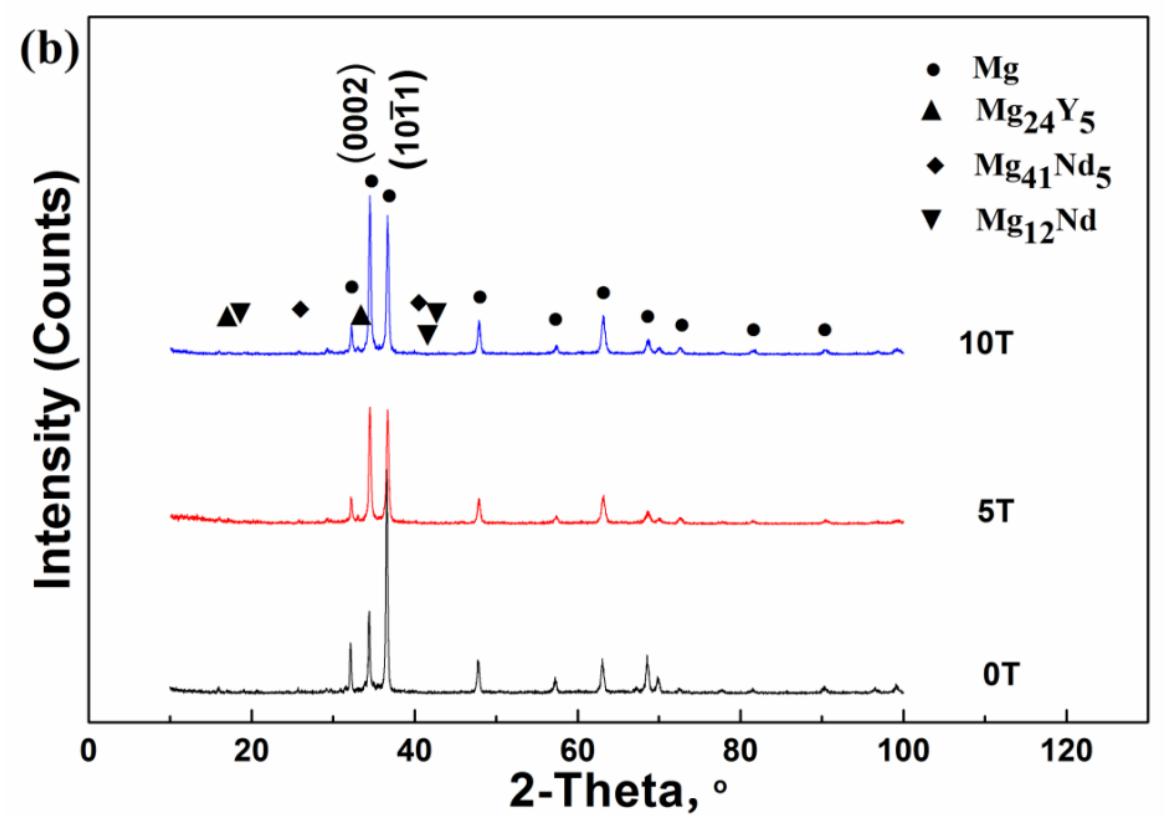


Figure 3 X-ray diffraction patterns consist of as-extruded and the disks of WE43 by HPT for 5 and 10 turns.

Increasing the numbers of rotation, the diffraction peak heights of the $\alpha-\mathrm{Mg}$ matrix phase changed. Thus, the intensity of the (0002) plane was enhanced and the $(10 \overline{11})$ pyramidal plane was reduced, thereby indicating that the $\mathrm{Mg}$ alloy has a preferred orientation, ${ }^{[25,26]}$ as shown in Figure 3, Which due to twins appear after HPT deformation for 5 turns. In addition, increasing the numbers of rotation, compression deformation also affects the increase in (0002) intensity. This transformation leads to a decrease in the available slip systems.
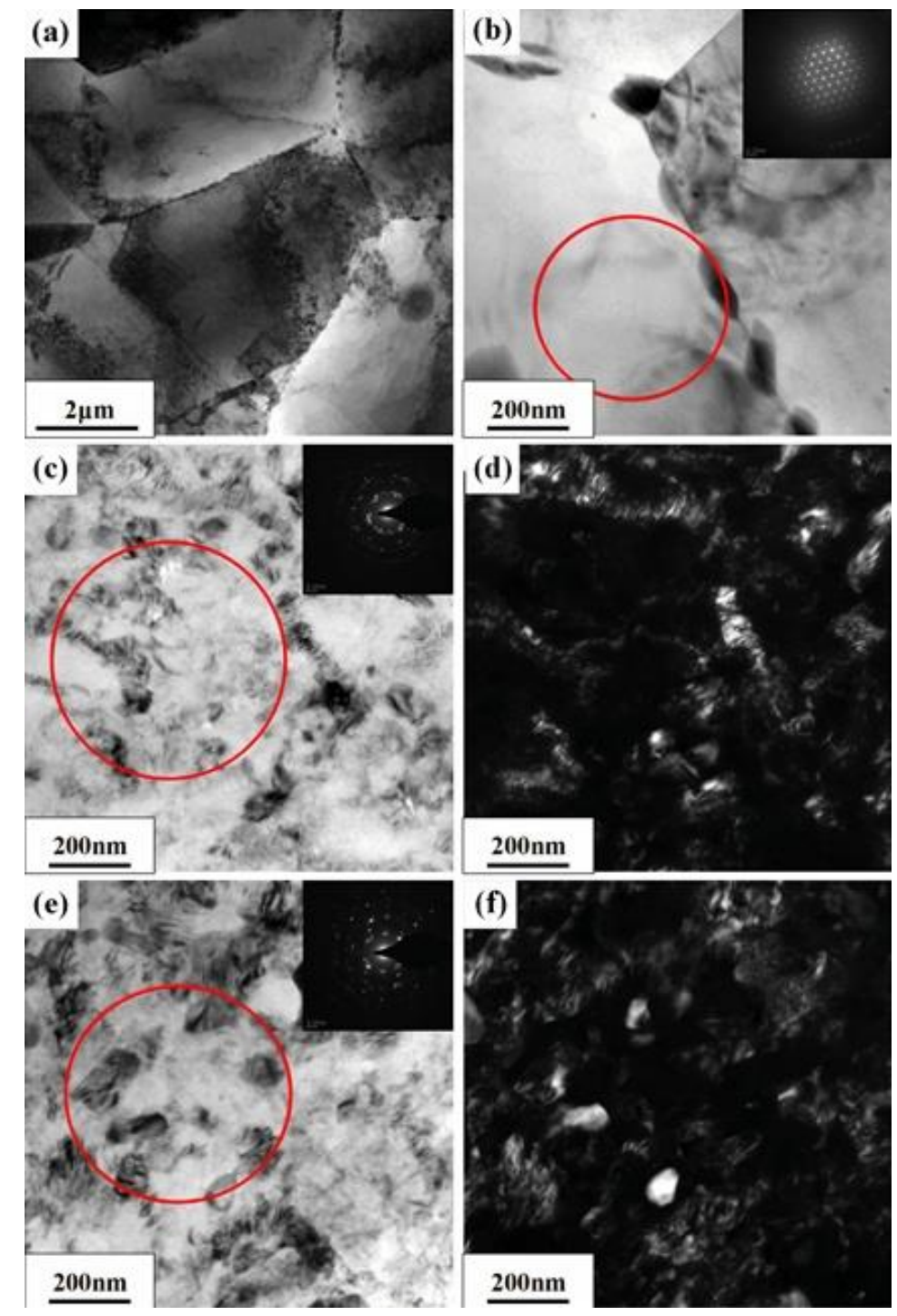

Figure 4 TEM micrographs of WE43 alloy: (a) and (b)images showing the initial as-extruded 
structure and the images after HPT processing at half-radius distance from the center of disk: (c) bright-field image and (d) dark-field image of 5 turns; (e) bright-field image and (f) dark-field image of 10 turns.
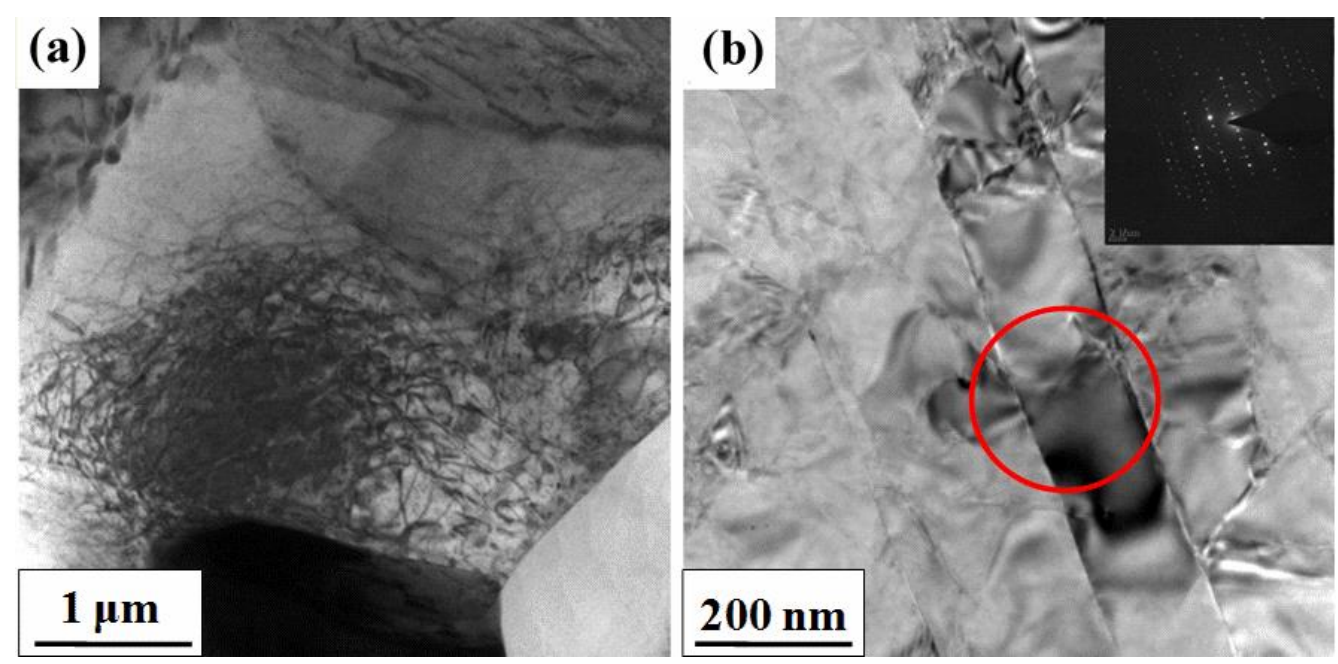

Figure 5 TEM micrographs of WE43 alloy: (a) dislocations accumulation in the interior of the eqiaxed grains after extrusion deformation; (b) twins in the interior of the grains after HPT for 5 turns.

Figures 4 and 5 reveal more detailed microstructural characteristics consisting of the asextruded sample and the disks after HPT processing. Figures 4(a) and 4(b) show TEM images of the as-extruded sample with the corresponding SAED pattern indicating a gray granular secondary phase with size of $\sim 150-200 \mathrm{~nm}$ distributed at the grain boundaries. Figure 5(a) reveals the accumulation of a high density of dislocations and dislocation tangles in the interior of an equiaxed grain after extrusion. The TEM microstructures near the one-half radius of the disks after HPT for 5 and 10 turns are also shown in Figures 4(c) and (d) and Figures 4(e) and (f), respectively. The SAED pattern that appears as polycrystalline diffraction spots indicates the formation of sub-grains. ${ }^{[27]}$ The sub-grain size after HPT for 5 turns is $\sim 300-400 \mathrm{~nm}$ and it is further reduced to $\sim 200-300 \mathrm{~nm}$ after HPT for 10 turns. There is evidence for deformation twins in the interior of the grain using the SAED pattern inserted in Figure 5(b) after HPT for 5 turns but there was no evidence for twinning after 10 turns. In practice, twinning is a significant mechanism for grain refinement after 5 turns because the 
appearance of twins is beneficial for dislocation glide since a steady stream of dislocations generally appears within the twins with increasing shear strain. Subsequently, the interaction between twinning and dislocation glide leads to the subdivision of grains and grain refinement.

When the HPT processing is continued, as shown in Figures 4(e), 4(f), twins gradually disappear. Careful inspection showed that the dislocation density increases and the interaction between dislocations, as well as between dislocations and grain boundaries, results in the formation of dislocation accumulations and tangles. Thereafter, there is a transformation into dislocation cells and sub-grains and the numbers of dislocation tangles are gradually reduced as well as their overall size as shown in Figure 6(a). In addition, the formation of nonequilibrium boundaries and dislocation cells via dislocations motion gives rise to the subdivision of grains. Thus, a partial dislocation cell has formed a complete fine grain near the grain boundary triple point in Figure 6(b). When the shear strain increases to a certain extent, the levels of microstructural refinement tend to reach a stable condition.
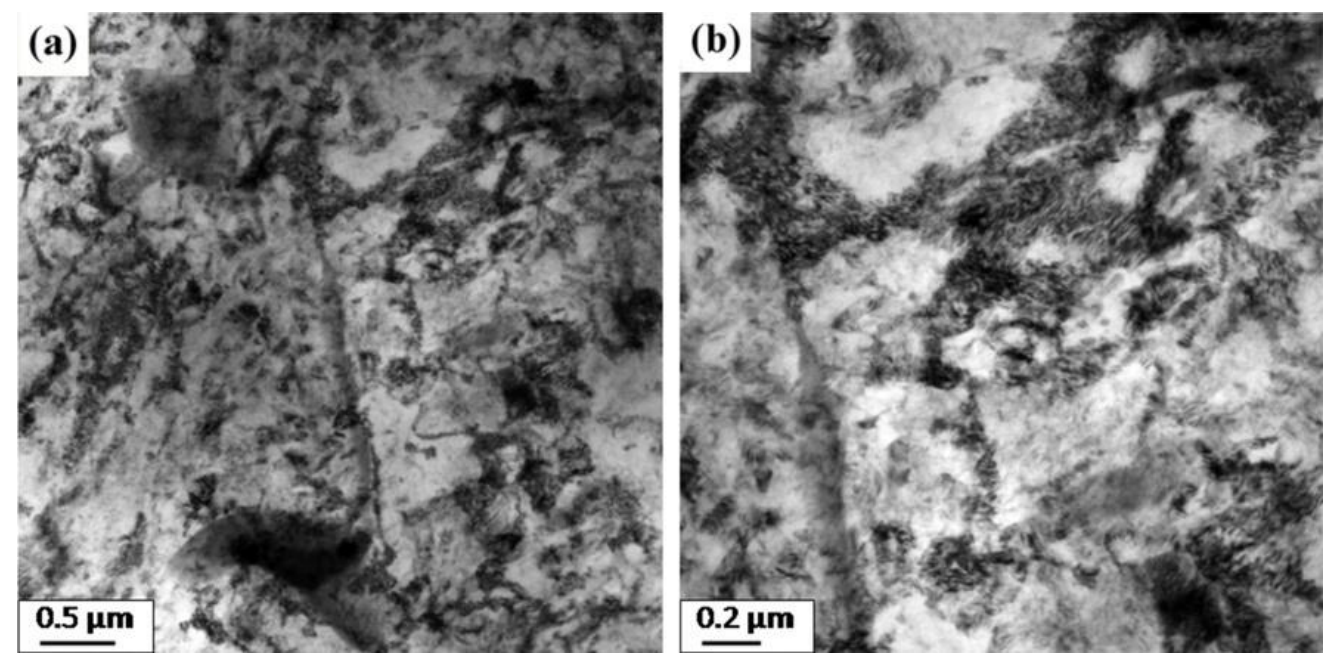

Figure 6 The evolution of dislocation structure in WE43 alloy during HPT deformation for 10 turns:

(a) dislocation cell and subboundaries; (b) equiaxed grain.

Finally, the occurrence of streaking in both the disk for 5 turns and the disk for 10 turns indicates the presence of residual stresses in the structure of these materials. There have been several attempts 
to directly evaluate the nature of the long-range internal stresses in metals processed using SPD techniques. $^{[28-30]}$

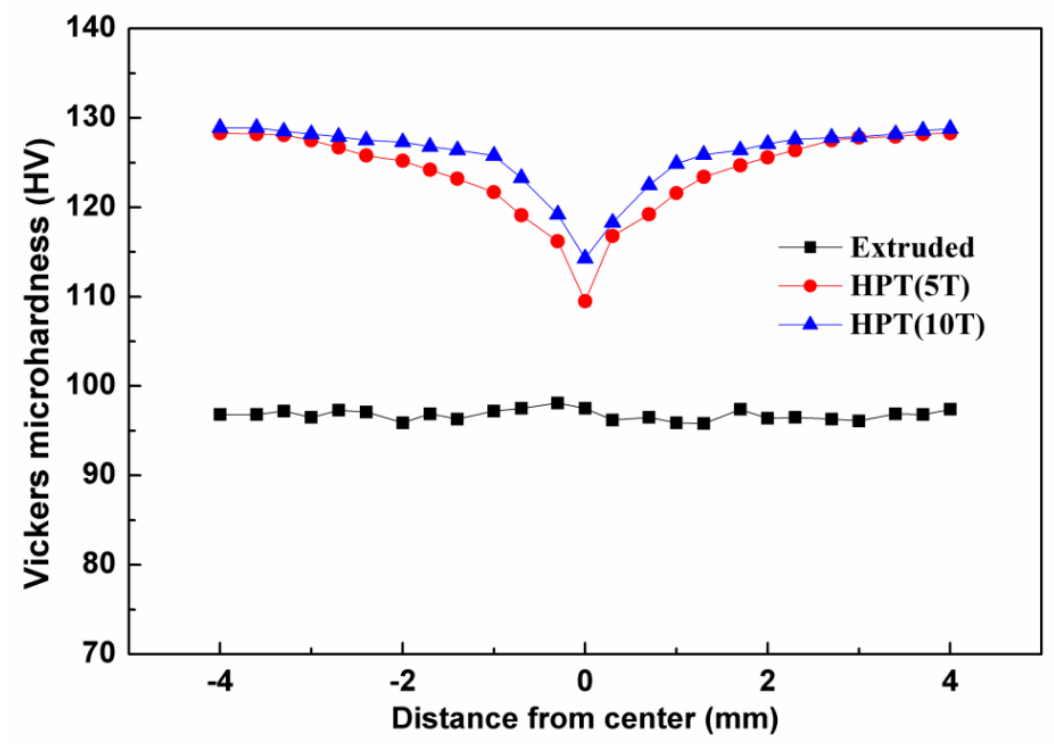

Figure 7 The relationship between microhardness and distance from the center of the disk for WE43 alloy: after extrusion deformation and after HPT processing for different numbers of turns.

\subsection{Mechanical characterization}

The Vickers microhardness values are shown in Figure 7 for samples after processing by HPT for 5 and 10 turns where the hardness values were recorded along each disk diameter and the lower microhardness values were measured in the extruded condition prior to HPT. The average hardness values of the extruded sample are $95 \mathrm{Hv}$. The results after the HPT deformation display a gradual evolution of microhardness across the disk diameters with different numbers of rotations. The hardness values in the center of the disk increase to $\sim 109 \mathrm{Hv}$ and there is an increase to $\sim 129 \mathrm{Hv}$ at the edge of the disk after processing by HPT for 5 turns. Subsequently, with an increase in the numbers of torsional rotations, the hardness values in the center of the disks increase to $113 \mathrm{Hv}$ after 10 turns but the values in the center remain exceptionally low by comparison with the values at the edge of the disk. These trends may be displayed in a three-dimensional representation as shown in Figure 8 for (a) 5 and (b) 10 turns. Thus, the hardness gradually evolves with increasing shear strain 
towards a more uniform condition such that the region of lower hardness in the center of the disk becomes smaller with increasing strain.
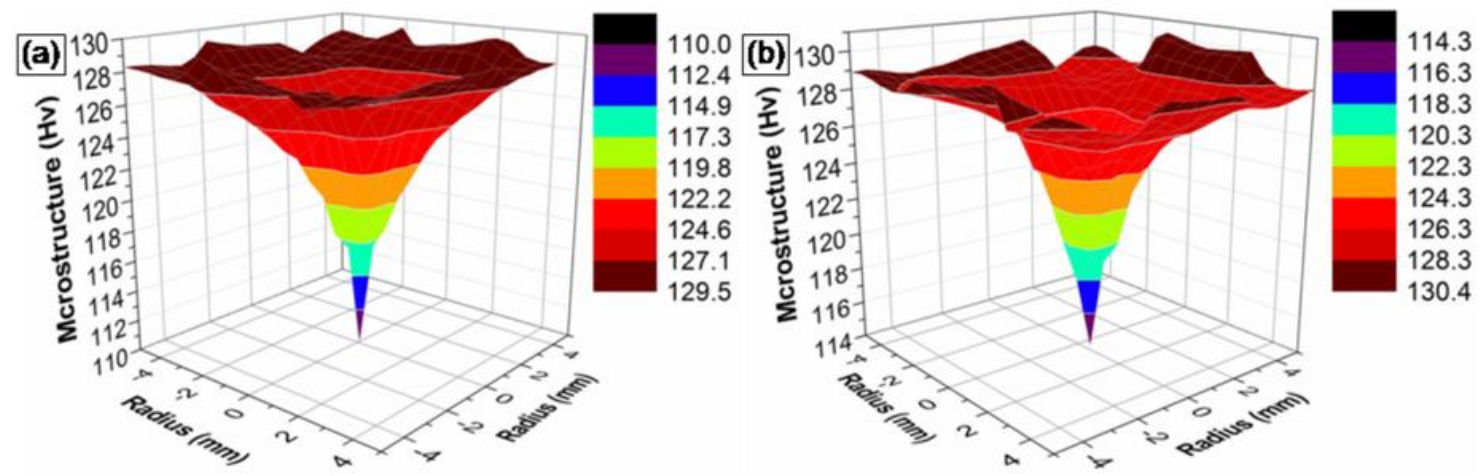

Figure 8 The 3D microhardness distrubution of WE43 alloy after HPT processing: (a) 5 turns; (b)10 turns.

Essentially, the evolution of hardness values is attributed to the shear strain accumulation at different positions within each disk during the deformation process. The largest deformation is at the specimen edge and the smallest deformation is at the center of the disk. This suggests there will be an inhomogeneity across the disk but, by contrast, many results show that this inhomogeneity gradually disappears with increasing deformation. For example, there is a gradual evolution towards microhardness homogeneity in numerous metallic alloys such as Al-4wt.\%Mg, ${ }^{[31]} \mathrm{AZ31},{ }^{[32]} \mathrm{Al}-6063$ and $\mathrm{Cu}-0.1 \% \mathrm{Zr}^{[33,34]} \mathrm{A}$ detailed review is now available summarizing these trends for a large number of metals. ${ }^{[35]}$ Furthermore, the evolution towards homogeneity is consistent with the prediction of strain gradient plasticity modeling. ${ }^{[36]}$

For the WE43 alloy, a fully homogeneous hardness distribution was not achieved even after 10 turns although the lower hardness region in the center of the disk tended to become smaller. There are also some other reports where a homogeneous hardness distribution was not achieved even after large numbers of revolutions of HPT: for example, a saturation microhardness was not achieved in a NiTi alloy after 40 turns or in a $\beta$-titanium alloy after 50 turns. ${ }^{[37,38]}$ 


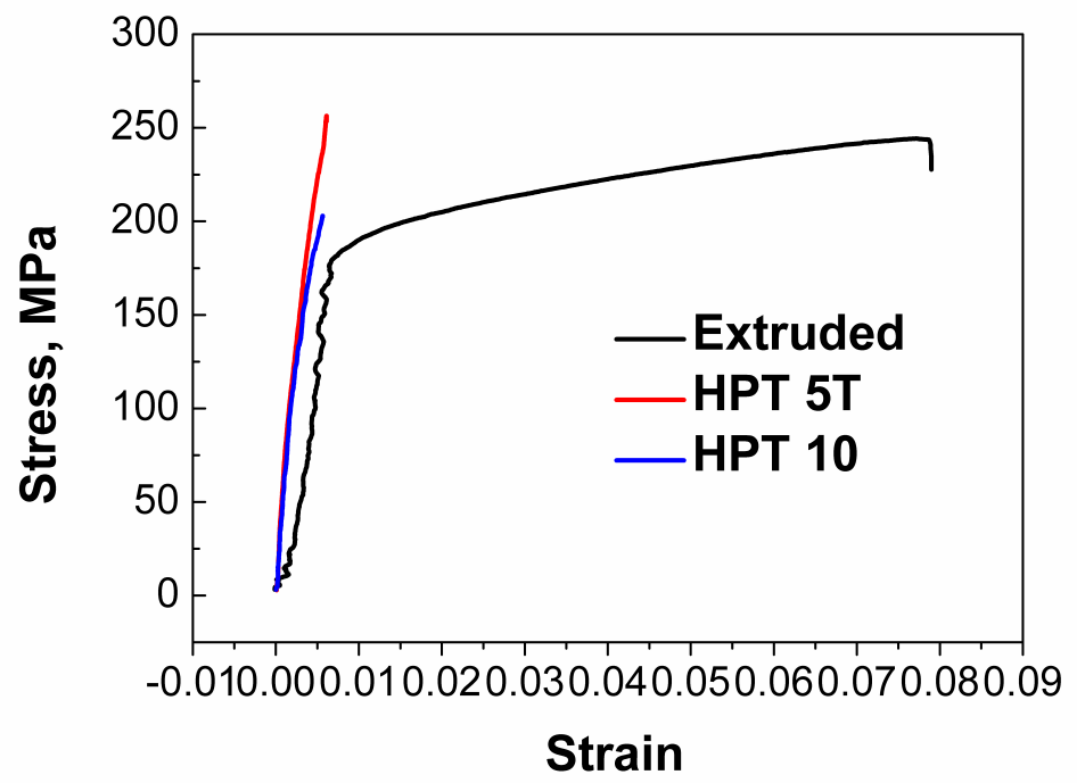

Figure 9 The stress-strain curves at different conditions consisting of the as-extruded sample and the disks after processing for 5 turns and 10 turns.

The mechanical properties of the WE43 alloy samples consisting of the extruded sample and the HPT samples with different numbers of revolutions are presented in Figure 9 and the results of the tensile testing are listed in Table 1. The ultimate tensile strength (UTS) and elongation for the extruded WE43 alloy was $\sim 244 \mathrm{MPa}$ and $8 \%$, respectively, due to grain refinement strengthening and solution strengthening. ${ }^{[39]}$ Table 1 shows that the elongation of the samples decreased consistently after HPT for 5 and 10 turns and the elongations to failure also decreased. There are two reasons for the decrease in the elongations. First, there is the inevitable paradox of strength and ductility which states that strengthening by SPD processing will lead to a corresponding decrease in the measured ductility. ${ }^{[40]}$ Second, the magnesium alloy shows very brittle characteristics after the deformation of HPT. Nevertheless, the present results demonstrate a significant increase in the tensile strength after hot extrusion followed by HPT processing. Thus, the UTS was measured as $\sim 256 \mathrm{MPa}$ after 5 turns but subsequently was reduced to $202 \mathrm{MPa}$ after 10 turns.

Table 1 Tensile testing results 


\begin{tabular}{ccc}
\hline & UTS [MPa] & Elong [\%] \\
\cline { 2 - 3 } as-extruded & 244 & 8 \\
$5 \mathrm{~T}$ & 256 & 0.5 \\
$10 \mathrm{~T}$ & 202 & 0.5 \\
\hline
\end{tabular}
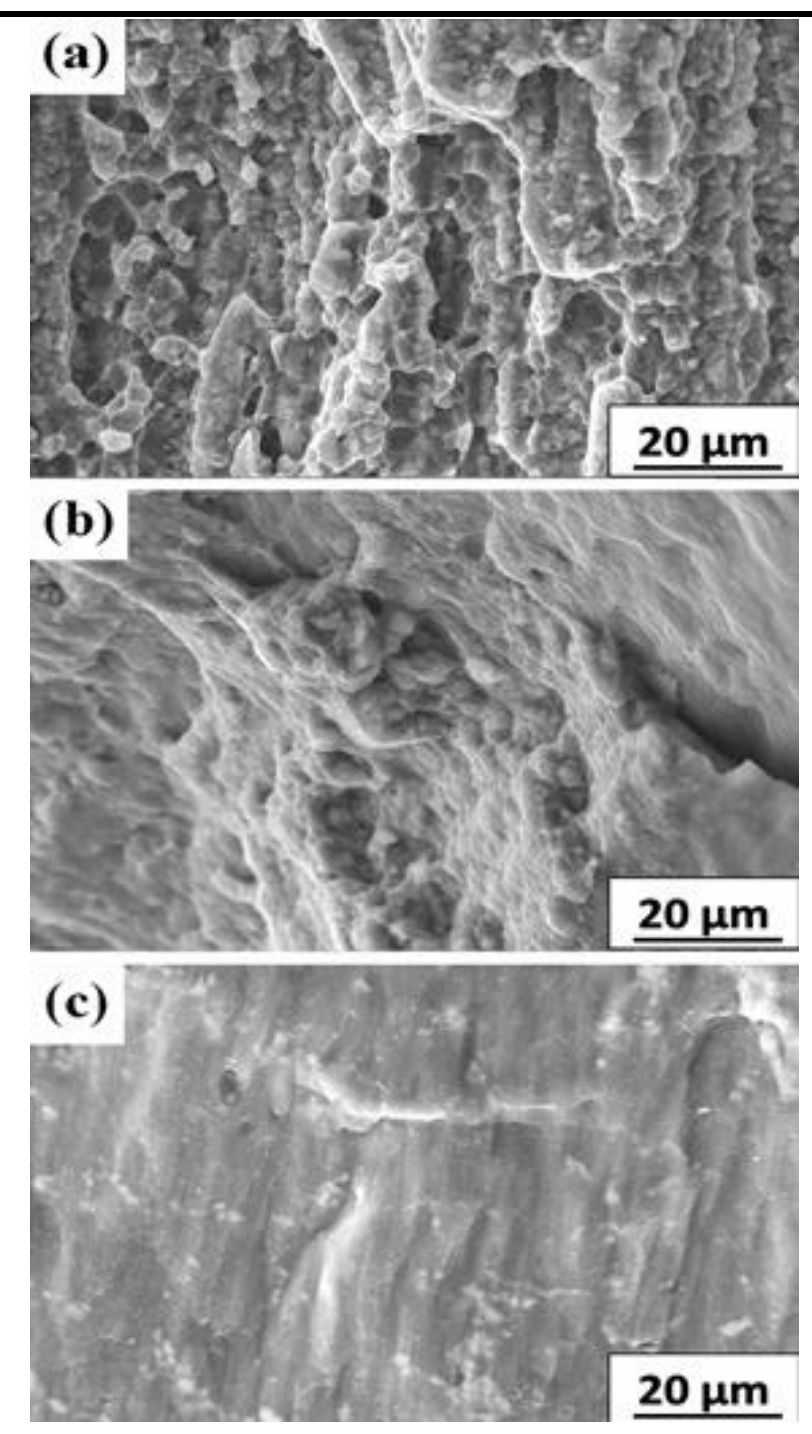

Figure 10 WE43 magnesium alloys tensile fracture morphology: (a) extruded sample; (b) after HPT processing for 5 turns and (c) after HPT processing for 10 turns.

The overall SEM micrographs of the evolution of the fracture morphology are shown in Figure 10. Inspection shows there are a large of number of dimples and tearing ridges having different sizes at the fracture surface of the extruded sample in Figure 10(a) thereby indicating that the fracture mode is mainly ductile fracture during the stretching process. As shown in Figure 10(b) after 5 turns, 
the presence of a limited number of dimples and fissures in the cleavage plane demonstrates that the fracture mode is a mixture of ductile and brittle fracture. The fractograph of the sample after 10 turns is shown in Figure 10(c) and it is apparent that there are no dimples and failure occurs by cleavage. Thus the ductility and strength was weakened after 10 turns of HPT because of the reduction in the number of active slip systems.

\section{Summary and conclusions}

(1) A magnesium WE43 alloy with an initial grain size of $\sim 12 \mu \mathrm{m}$ was processed by HPT to produce an ultrafine-grained microstructure and the sub-grain size is $\sim 200-300 \mathrm{~nm}$ after 10 turns.

(2) The microhardness values on the surfaces of HPT disks increased significantly with torsional straining. The hardness values were low in the central region but higher hardness values were recorded at the edges of the disks. There was a very slow hardness evolution towards a more homogenous condition and the hardness variation across the disk was large even after 10 revolutions of HPT.

(3) The overall mechanical properties of the WE43 alloy were changed through HPT processing. Thus, the ultimate tensile strength increased from $\sim 244 \mathrm{MPa}$ to $\sim 256 \mathrm{MPa}$ after 5 turns due to finegrain strengthening and dislocation strengthening but it was reduced to $202 \mathrm{MPa}$ after 10 turns because of the inhibitory effect of grain boundary on dislocation movement decreased. Observations on the fracture surfaces revealed a corresponding change in fracture from ductile to brittle.

\section{References}

[1] J. Reifenrath, N. Angrisani, N. Erdmann, A. Lucas, H. Waizy, J. M. Seitz, A. Bondarenko, A. Meyer-Lindenberg, Biomed. Mater. 2013, 8, 045012.

[2] P. Zartner, R. Cesnjevar, H. Singer, M. Weyand, Catheter. Cardiovasc. Interv. 2005, 66, 590.

[3] H. M. Wong, K. W. Yeung, K. O. Lam, V. Tam, P. K. Chu, K. D. Luk, K. M. Cheung, 
Biomaterials 2010, 31, 2084.

[4] S. J. Kalita, S. Bose, H. L. Hosick, A. Bandyopadhyay, Mater. Sci. Eng. C 2003, 23, 611.

[5] H. S. Brar, J. P. Ball, I. S. Berglund, J. B. Allen, M. V. Manuel, Acta Biomater. 2013, 9, 5331.

[6] X. N. Gu, Y. F. Zheng, L. J. Chen, Biomed.Mater. 2009, 4, 065011.

[7] O. B. Kulyasova, R. K. Islamgaliev, Y. H. Zhao, R. Z. Valiev, Adv. Eng. Mater. 2015, 17, 1738

[8] A. Vinogradov, Adv. Eng. Mater. 2015, 17, 1710.

[9] W. R. Zhou, Y. F. Zheng, M. A. Leeflang, J. Zhou, Acta Biomater. 2013, 9, 8488.

[10] N. I. Z. Abidin, A. D. Forno, M. Bestetti, D. Martin, A. Beer, A. Atrens, Adv. Eng. Mater. 2014, 17,58 .

[11] Y. Chen, Y. Song, S. X. Zhang, J. A. Li, C. L. Zhao, X. N. Zhang, Biomed. Mater. 2011, 6, 025005 .

[12] J. X. Zheng, B. Chen, Adv. Eng. Mater. 2016, 18, 1332.

[13] Y. Beygelzimer, Y. Estrin, R. Kulagin, Adv. Eng. Mater. 2015, 17, 1853.

[14] H. L. Yu, C. Lu, A. K. Tieu, H. J. Li, A. Godbole, S. H. Zhang, Adv. Eng. Mater. 2015, $18,754$.

[15] E. Mostaed, M. Vedani, M. Hashempour, M. Bestetti, Biomatter 2014, 4, e28283.

[16] W.-J. Kim, G. E. Lee, J. B. Lee, Adv. Eng. Mater. 2009, 11, 525.

[17] M. Furukawa, Z. Horita, T. G. Langdon, Adv. Eng. Mater. 2001, 3, 121.

[18] P. Bazarnik, Y. Huang, M. Lewandowska, T. G. Langdon, Mater. Sci. Eng. A 2015, 626, 9.

[19] A. V. Nagasekhar, S. C. Yoon, J. H. Yoo, S.-Y. Kang, S. C. Baik, M. I. A. EI Aal, H. S. Kim, Mater. Trans. 2010, 5, 977.

[20] J. Vrátná, M. Janeček, J.Čížek, J. L. Dong, E. Y.Yoon, J. Mater. Sci. 2013, 48, 4705.

[21] R. B. Figueiredo, P. H. R. Pereira, M. T. P. Aguilar, P. R. Cetlin, T. G. Langdon, Acta Mater. 
2012, 60, 3190 .

[22] A. P. Zhilyaev, G. V. Nurislamova, B. K. Kim, M. D. Baró, J. A. Szpunar, T. G. Langdon, Acta Mater. 2003, 51, 753.

[23] M. I. A. EI Aal, E. Y. Yoon, H. S. Kim, Metall. Mater. Trans. A 2013, 44, 2581.

[24] M. Liu, H. J. Roven, T. Ungár, L. Balogh, M. Y. Murashkin, R. Valiev, Mater. Sci. Forum 2008, $584-586,528$.

[25] C. M. Liu, B. F. Li, R. Wang, H. Z. Li, Z. Y. Chen, Chin. J. Nonferr. Metal. 2010, 20, 171.

[26] D. Zhao, J. Zhou, Y. Liu, X. Dong, J. Wang, Y. S. Yang, Acta Metall. Sin. (China) 2014, 50, 41.

[27] J. Bai, F. Xue, S. N. Alhajeri, T. G. Langdon, Mater. Sci. Forum 2011, 667-669, 391.

[28] S. N. Alhajeri, A. G. Fox, T. G. Langdon, Acta Mater. 2011, 59, 7388.

[29] I.-F. Lee, T. Q. Phan, L. E. Levine, J. Z. Tischler, P. T. Geantil, Y. Huang, T. G. Langdon, M. E. Kassner, Acta Mater. 2013, 61, 7741.

[30] T. Q. Phan, I.-F. Lee, L. E. Levine, J. Z. Tischler, Y. Huang, A. G. Fox, T. G. Langdon, M. E. Kassner, Scr. Mater. 2014, 93, 48.

[31] X. H. Yang, J. H. Yi, Y. Du, M. Song, J. Mater. Eng. Perform. 2016, 25, 1909.

[32] J. Stráská, M. Janeček, J. Gubicza, T. Krajňák, E. Y. Yoon, H. S. Kim, Mater. Sci. Eng. A 2015 , $625,98$.

[33] M. Das, G. Das, M. Ghosh, M. Wegner, V. Rajnikant, S. GhoshChowdhury, T. K. Pal, Mater. Sci. Eng. A 2012, 558, 525.

[34] J. Wongsa-Ngam, M. Kawasaki, Y. Zhao, T. G. Langdon, Mater. Sci. Eng. A 2011, 528, 7715.

[35] M. Kawasaki, J. Mater. Sci. 2014, 49, 18.

[36] Y. Estrin, A. Molotnikov, C. Davies, R. Lapovok, J. Mech. Phys. Solids 2008, 56, 1186. 
[37] H. Shahmir, M. Nili-Ahmadabadi, Y. Huang, T. G. Langdon, J. Mater. Sci. 2014, 49, 2998.

[38] K. Sharman, P. Bazarnik, T. Brynk, A. G. Bulutsuz, M. Lewandowska, Y. Huang, T. G. Langdon, J. Mater. Res. Technol. 2015, 4, 79.

[39] D. X. Liu, Y. T. Ding, T. B. Guo, X. Q. Qin, C. G. Guo, S. K. Yu, S. L. Lin, Biomed. Mater. 2014, 9,015014

[40] R. Z. Valiev, I. V. Alexandrov, Y. T. Zhu, T. C. Lowe, J. Mater. Res. 2002, 17, 5.

\begin{abstract}
Abbreviations
(HPT), high-pressure torsion; (SPD), severe plastic deformation; (ECAP), equal-channel angular pressing; (SEM), scanning electron microscope; (EDS), energy dispersive spectrometer; (TEM), transmission electron microscopy; (SAED), slected area electron diffraction; (XRD), X-ray diffraction; (UTS), ultimate tensile strength
\end{abstract}

\title{
Table of contents
}

Microstructure evolution of HPT-processed resorbable WE43 alloy is investigated. A WE43 alloy with an initial grain size of $\sim 12 \mu \mathrm{m}$ is processed by HPT to produce an ultrafine-grained microstructure and the sub-grain size is $\sim 200-300 \mathrm{~nm}$ after 10 turns. The microhardness shows significant improvement with increasing dislocation density. The tensile strength firstly increases and 
then decreases, while the elongation decreases after HPT deformation.

Dexue Liu *, Xin Pang, Denglu Li, Chenggong Guo, Jittraporn Wongsa-Ngam, Terence G. Langdon, Marc A. Meyers

Xin Pang

Denglu $\mathrm{Li}$

Chenggong Guo

Jittraporn Wongsa-Ngam

Terence G. Langdon

Marc A. Meyers
Title: Student

Title: Student

Title: Student

Title: Dr.

Title: Professor

Title: Professor

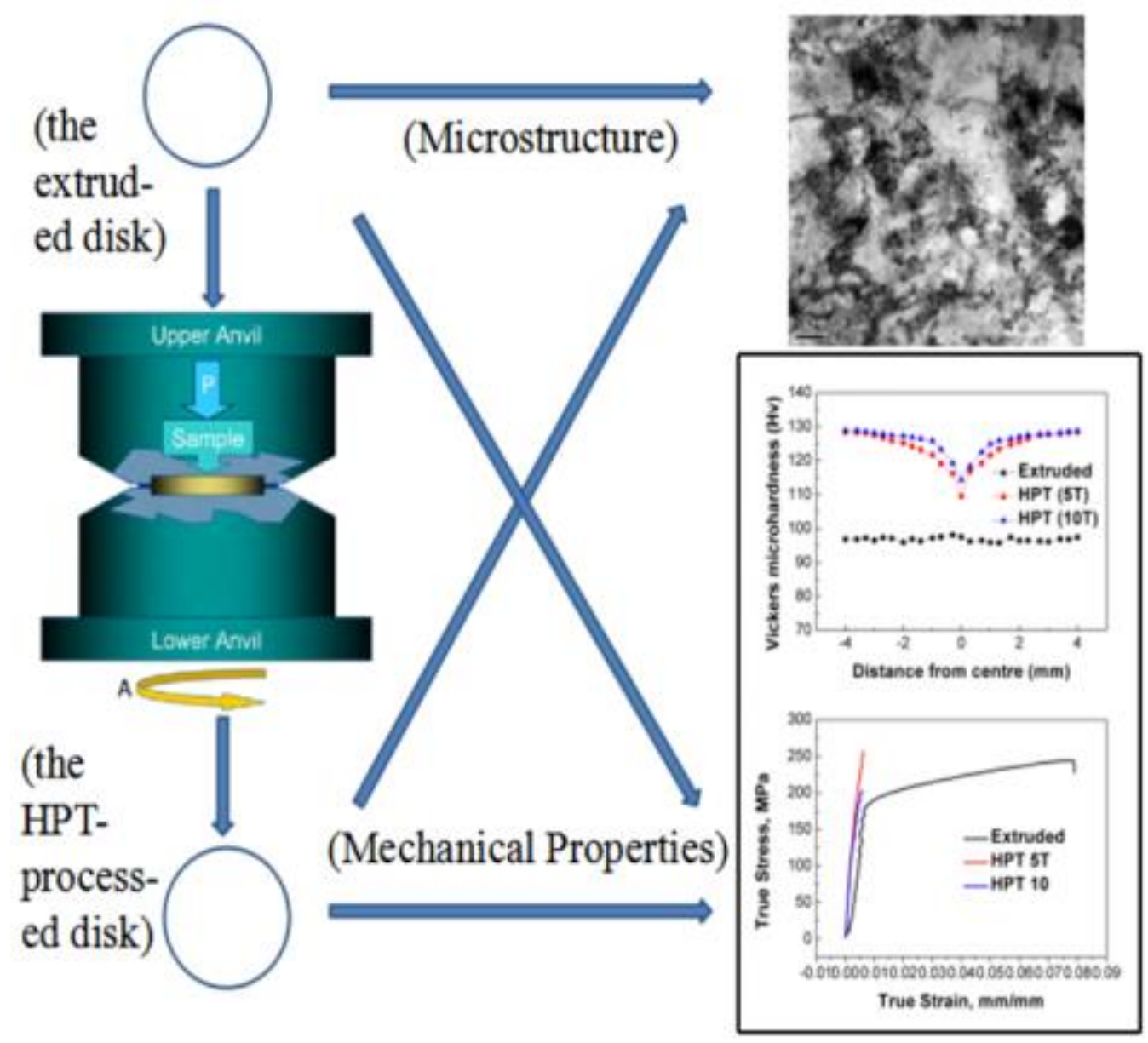

